\title{
Cultural Spectrum in Arvind Adiga's Selection Days
}

\author{
Ankur Yadav \\ Research Scholar \\ Department of English \\ Dr Bhimrao Ambedkar University \\ Agra,India \\ ankur.bpsetah@gmail.com
}

\begin{abstract}
Cultural Studies have played a pivotal role in understanding and evaluating the power dynamics of the social, political, economic and ethical world order by empirically engaging and focusing on the present-day culture, tracing its historical roots and explicating its attributes with reference to a particular literary text and its reception in a society. Arvind Adiga, the Man-Booker Prize winning Indo-Australian author, in Selection Day, has adroitly detailed how cricket as an individual entity impacts the cultural phenomena of a society by confronting its inherent myriad issues. The narrative delves deep into the lives of two siblings - Radha and Manju, witnesses the dramatic turnaround of events and tries to capture the themes of unfulfilled desires and preordained destinies. The novel also explores how the sport holds different meanings and significance for different characters, each of whom view the game in the light of their own ideology. The author foresees and sensitizes the theme of homosexuality, which is still a taboo and been unheard of, within the sports fraternity. Adiga's critique of the parental felony, embodied in Mohan Kumar, and its repercussions is the most compelling theme at the heart of
\end{abstract}


this work of fiction. Selection Day powerfully binds together the societal phenomena of class construction, unquenchable thirst for money, sexual orientations and ideologies with a single thread and studies how culture, in itself, is an ever-evolving phenomenon.

Keywords: Cultural Studies, Selection Day, Sports, Fiction, Homosexuality, Parental felony.

Cultural Studies designates an inter-disciplinary field of study that investigates the manifold factors pertaining to production, reception and cultural significance of a literary text. A prominent endeavor is to analyze the functioning of social, economic and political frameworks which manifest the yielding of various cultural phenomena, bestow them with social meanings, assigning the relative values and their acceptance as truth. It views these cultural phenomenon assigned to meanings and values as the product of prevalent and dominant social forces and conventions, and that may either exhibit or oppose the dominant structure of power in a particular domain of culture. A major attribute of Cultural Studies deals with the subversion of hierarchical criticism between 'high literature' and what is denominated as literature of the lower forms that appeal to the masses. Categorically, it prefers the Popular Fiction over Literary Canons and moves centripetally to the literary texts that have been aesthetically ignored or marginalized by the European thinkers.

This paper aims to study Selection Days as a cultural spectrum that captures Cricket as a multifaceted entity and highlights the social, political and economic impact of the sport on the society, for a cross-disciplinary study. Adiga, through the game of cricket artistically webs the themes of unrequited desires, filial deity, unexplored sexuality, insatiable quest for money and inevitable fate. Cricket, as a sport is not a mere spectator event but also a participating entity and an impeccable cultural feature of the social, political and economic life in India. The novel traces 
the journey of two budding cricketers residing on the outskirts of Mumbai, incongruently not to the path of glory but highlighting the impediment on the path to success and the paths closed off by cricket. These themes and their nebulous adherences formulate a narrative unheard in the cricketing history and apprehend the social, political, economic and ethical issues prevalent in the contemporary society. In Adiga's buoyant and socially penetrating novel, Manju and his brother enters "filtration system that sucks in strong wrists, quick school teams, club championships, and friendly matches for years and years, and then one sudden morning pours them out into an open field where two or maybe three new players will be picked for the Mumbai Ranji Trophy team" (Adiga 6).Selection Days, on the outset, feels prone to fall prey to the linear pattern of a sports fiction. Ardent dreams of cricket glory, sibling rivalry, years of patting the cricket pitch and sweating under the scorching sun in the cricket ground leading to the ultimate glory on the Selection Day. However, the novel is not homogenous in context and does not follow the linear path to glory but rather the other avenues in their lives, ceased by the game of cricket.

Selection process in cricket usually begins with club cricket or School cricket leading to the district team. Subsequent selection into the State team and from there finally breaking into the national cricket team is how it concludes. Society has always glorified the talent, temperament and sheer hard work for the selection in a sports team. It is quite uncommon to hear that issues like class, religion or sexuality have annihilated the dreams of a sport like cricket. There have been numerous inspirational stories from rags to riches in sports but weighed only on exceptional talent. However, it has brutally ignored the gnawing issues and steep hurdles that these sportsmen face in their lives in the society. 
For all those years, who are they competing against? Is it only about triumphing in the sports? Adiga, in this book, has explored what goes beyond the enticing sports narratives. In the novel, we witness how Radha and Manju struggle with the cricketing nuances and psychological issues respectively and at times, coherently. The social penetration of the novel is the most acute when Ramnath, the ironing man from Dahisar broke the wonderful news of his daughter's admission in a prestigious college in America to a destitute Mohan Kumar. The news left Mohan Kumar contemplating the very 'truth' of his life.

"All his life Mohan Kumar had warned his sons about the danger from other talented boys: he had forgotten that the real threat was from the normal and the average, like this smug shirtironer from the Shastrinagar slum. These were the people who had destroyed Radha: they and their normal sons"(Adiga 220).

The incident aptly mirrors the idea of truth which is endowed with meaning and its relevance in the society because of the prevailing social forces. However, the cultural studies endeavor to inculcate resistance against these dominant social forces and determinants to endue the new meanings.

The epicenter of the novel is Adiga's critique on the contemporary parenthood. Adiga has foregrounded the parents who attempt to pursue and realize their own undermined, diminished and failed dreams through their naïve progenies. It is a social and an ethical infringement to weigh someone, knowingly with your own dreams. They unknowingly deny the freedom of their child, cage them psychologically and captivate their choices, needs, desires, urges, speeches and even relations with other children. As a result, these children develop the feelings of resentment and bitterness towards the society in general. The controlled life of these children impedes their own abilities and psyche. The persistent stress of cutthroat competition and performance pressure 
in addition, yields soulless performances before being ended as a fiasco in the later stages of their lives. In Selection Days, both Radha and Manju suffer this inevitable fate. Radha develops an ever growing cynicism towards his father and society that ostensibly outcasts him from the social world presumably for his entire life. The mediocre performances of Manju result in him being left from the state cricket tea, making the glorious vision of selection in the national cricket team now a dwindled dream. Both the prodigal sons of Mohan Kumar failed to achieve what they could have because of their father's unrequited dreams being weighed on their back.

"And you could have become an engineer, a scientist, you could have gone to America by now. You could have sent me money from there, instead of - " (Adiga 271)

Selection Day also accentuates the conundrum of choice in one's life. The dramatic turnaround of events on the all-important and decisive Selection Day leads Manju being selected for the honor and his brother being left out, dejectedly. Manju's soulless performances shorten his career for a meager 10 years. At 27, when cricketers are usually at their prime, Manju is at crossroads to choose a career between playing and coaching the game. After the abrupt ending of his cricketing career, Radha fails to add any meaning to his life. He has never given a thought to anything except cricket his entire life, which has left him in oblivion about the life afterwards. He is an archetype of the protagonist who exhibits what happens when one is forced to pursue a life they do not want. The courses of the lives of the two brothers would have taken different shapes if Selection Day had favorable outcomes. Had Radha performed better than his younger brother on the Selection Day, his career would not have succumbed to a premature death and would have been a career more decorated and glorified than Manju. On the other hand, Manju who has better consonance with the field of science than cricket would have excelled far more in the science arenas than the cricket field as evident from the storyline of the novel. The novel 
culminates in a depressed present echoing the underlined idea of choice; if these boys had the freedom of choosing their own paths, the future must have been better embellished.

Cultural studies either oppose or exhibit the dominant power structure and robust determinant in the society. When a businessman wearing a football jersey enters in the narrative to sponsor these children one can lucidly manifest that cricket isn't a mere sport, anymore. Cricket in India, is a billion dollar business. The amount of revenue and incremental power it has advent upon, is an unparalleled entity in the country. Every businessman wants to encash the lucrative opportunities cricket has bolstered. It is not an insignificant episode when in a business summit Mrs. Rupinder, an NRI investor, is enticed to the scholarship programme of Anand Mehta. This episode epitomizes the financial viability of cricket. For Anand Mehta, Cricket is all about spinning money. It is his 'latest business venture' where nothing could go wrong. Through Mehta, Adiga also reminds us of how cricket, in yesteryears, has not been left bereft of corrupt practices. In fact the innate desire of money in Mehta arises when one of his friends, a close associate in BCCI tells him about how an ODI match between India and Sri Lanka was one of the many fixed instances. Cricket has certainly brought in loads of money but at the same time, has also brought in the unethical practices to make more and more money. This unflinching quest of money can drive a man to the level of insanity where he can force a teenager to drink alcohol and even delve him down to dream to fix a cricket match one day. This menace of corruption is a double edged sword - on one hand, it brings the crusader like Mehta in the game and on the other, it horrifies the ever-dreaming father like Mohan Kumar. This ruthless power and the unethical factors make him fear more about the selection of both of his sons and impelled him to visage Javed Ansari as the principal threat to his sons ultimately ending in relentless cricket practice. 
Among the many tenets of culture and society the novel explores, the theme of confounding sexuality is the most striking of them all. Adiga has formulated even his minor characters with formidable depth and pathos. Javed, the homosexual boy, has created a ripple effect enough to stir the lives of Mohan Kumar and his sons, Radha and Manju. Apart from the three principal dangers of 'premature shaving, pornography and car driving', Mohan Kumar introduces one more impediment in the form of Javed Ansari, who will compete cutthroat against them on the Selection Day. According to Mohan Kumar, it is not Javed's cricketing pyrotechnics but instead his very presence and his love poems that seem to flummox his second best batsman in the world.

"Yes, this Ansari boy is a mongoose - a cunning furry mongoose - and only a snake can save my family now - a snake"(Adiga 164)

Javed agitates the sexual awakening of Manju. His attraction to Javed is undeniable and as the D-Day approaches, his sexuality becomes the primary agency of tension. Setting it against the backdrop of freedom, Adiga makes the relationship of Javed and Manju more mysterical. At the time of the publication of the novel, Homosexuality in India was a punishable offence. Adiga not only addresses the issue of homosexual culture in the society but extends it to the sport community as well. In a country where no sportsperson has come out openly as homosexual, Adiga, by depicting immense challenges, gently confutes the possibility of the same in the foreseeable future.

Adiga has artistically created a multiverse where Cricket, a sport, forms different meanings for different characters of the novel. These varied contours of Cricket confront diverse issues of our society. In India, some people enjoy Cricket as a sport, some adduce it to nationalism and some consider it a business venture. For Mohan Kumar, success in cricket is the 
only panacea for a better life. Radha Kumar believes pioneering cricket is the ideal form of mastery over their destiny. Manju Kumar hates cricket as it thwarts his dream of becoming a forensic scientist. Tommy Sir lives for cricket only. Javed leaves Cricket because he thinks it impedes his freedom. Sofia is fascinated by the glamour of the game. Anand Mehta seeks only and only profit in his latest business venture. Karim Ali, the founder seeks cricket as an apparatus for sensationalism and glory. The Indian Masses tend to escape their frailties through cricket and seek comfort in the game. The author has used cricket as a thread to web the heterogeneous themes intrinsically. The game of cricket allows ascending readership fervor to amplify his voice regarding the issues of the society and culture, primarily freedom for children.

A close reading of Selection Day thus reveals Adiga's affinity towards addressing beleaguered and pertinent issues of the society. By exploring into the lives of budding cricketers in Mumbai and by weaving themes of confounding sexuality, darkness excelling excellence, parental felony and the role of adolescence and ambition, Adiga creates a spectrum mirroring a sociological dissection of the exasperating city and its culture. 


\section{References}

Adiga, Arvind. Selection Day. New Delhi: Harper Collins Publishers, 2016.

Abraham, MH and Harpham, G. Geofferey. A Glossary of Literary Terms, 10 ed. Delhi: Cengage Learning, 2014.

Barua, Micky and Das, Pratima. A Reading of Arvind Adiga's Selectetion Day as a Cricket Histrography. Studies in Indian Place Names, 2020, Volume 40, Issue 03; pp. 2740-2745.

Saeed, Samra and Ahmed, Abrar. A Critical Study of Narratology in Arvind Adiga's Selectetion Day. Studies in Indian Place Names, 2020, Volume 40, Issue 03; pp. 5267-5274.

Quinn, Analisa. "Cricket and Difficult Choices in 'Selection Day"”. npr, 8 Jan. 2017, www.npr.org/2017/01/08/507162506/cricket-and-difficult-choices-in-selection-day. 